\title{
The use of GnRH agonists in precocious puberty
}

\author{
D Mul and I A Hughes ${ }^{1}$ \\ Department of Pediatrics, Leiden University Medical Centre, 2300 RC Leiden, The Netherlands and ${ }^{1}$ Department of Paediatrics, Addenbrooke's Hospital, \\ University of Cambridge, Cambridge, CB2 OQQ, UK \\ (Correspondence should be addressed to EGAH van Mil at Department of Paediatrics, Jheronimus Bosch Medical Centre, PO Box 90153,5200 ME, \\ s'Hertogenbosch, The Netherlands; Email: vanmil@jbz.nl)
}

\begin{abstract}
In this review several aspects of gonadotrophin releasing hormone agonists (GnRHa) treatment in central precocious puberty (CPP) are highlighed. These include issues of the definition of precocity, assessment of CPP and thelarche variants. Indications for treatment with GnRH agonists are discussed, not only in CPP but also in children with other reasons to suppress central activation, e.g. adopted or developmental retardation. Finally, outcome data are summarized, both on growth and psychosocial parameters.
\end{abstract}

European Journal of Endocrinology 159 S3-S8

\section{Introduction}

GnRH agonist treatment in reproductive medicine is mainly devoted to two areas of interest. The first is the application in assisted reproduction, aimed at desensitization of the pituitary during ovarian stimulation (1). The second area of interest is the administration of longacting GnRHa preparations in the treatment of early or precocious puberty, where prolonged suppression of pituitary gonadotrophin secretion is required.

Central precocious puberty $(\mathrm{CPP})$ is characterized by premature awakening of the hypothalamic $\mathrm{GnRH}$ pulse generator with subsequent pulsatile gonadotrophin secretion. New insights into the physiology and pathophysiology of puberty have revealed the importance of both genetic and environmental factors in controlling the onset of puberty. For example, the potential role of exogenous pollutants (endocrine disrupting chemicals) in altering the age of onset of puberty is a phenomenon that highlights the sensitivity of the organism to environmental changes (2). There is also the argument from an evolutionary perspective that the trend towards an earlier onset of puberty as applied to females is an affirmation of the effects of adaptive mechanisms determined by distant ancestors (3). While early, as opposed to precocious, puberty may be considered an appropriate response biologically, there has evolved a mismatch because of delayed psychosocial maturation.

The identification of mutations in the gene for GPR 54 (KISS1R), a G-protein-coupled receptor, has highlighted

This paper was presented at the 5th Ferring International Paediatric Endocrinology Symposium, Baveno, Italy (2008). Ferring Pharmaceuticals has supported the publication of these proceedings. one cause of hypogonadotrophic hypogonadism with delayed puberty (4). Mutations affecting the ligand, KISS1, are also described in association with gonadotrophin-dependent precocious puberty (5). The present view is that kisspeptins have an essential role in the activation of the gonadotrophic axis (6). Despite these developments, the mainstay of the treatment of CPP is still targeted at the desensitization of the pituitary by agonists of native GnRH (7). This review summarizes the use of GnRHa in children, with particular emphasis on CPP and early puberty. Other applications in paediatric medicine will be discussed briefly.

\section{Issues in defining precocity}

It has been proposed that the age of onset of female puberty has declined based primarily on data gathered in the United States (8). However, the trend was more pronounced in black girls and similar data have not been replicated in Europe. Consequently, this review adheres to the current lower age limit of 8 years in girls (presenting with Tanner stage B2) and of 9 years in boys (Tanner G2 and/or testicular volume $\geq 4 \mathrm{ml}$ ). Children with pubertal development just above these age limits (e.g. a girl with B2 at 9.0 years of age) can be construed as just demonstrating early normal puberty. Nevertheless, in clinical practice, this raises similar concerns by parents as when true CPP occurs. For practical purposes, girls between 8 and 10 years, and boys between 9 and 11 years at onset of puberty have an early, but not precocious puberty, yet may in certain circumstances need to be considered for treatment intervention. 
A special group for consideration is children who have migrated from developing countries following international adoption and where menarche in girls is generally later than those in the Western countries (9). Studies from Denmark showed that adopted children were 10-20 times more likely to develop precocious puberty when compared with a reference Danish population (10). The aetiology of early maturation in adopted children, mainly girls, is not understood. The female preponderance implies a factor of central origin, but peripheral signals may be permissive or enhancing. Suggested contributing factors have included low birth weight, perinatal stress, changes in diet and exposure to environmental chemicals with endocrine disrupting effects in the country of origin (11).

\section{CPP and overlaps with thelarche variants}

Analysis of a large French sample of 353 girls with precocious puberty has highlighted the difficulty in sometimes distinguishing between premature thelarche and CPP in girls with breast development before the age of 8 years (12). Sixty per cent of the presentation occurred at 7-8 years of age; the principal anthropometric indices were an increased height SDS $(\geq+2$ SDS) in $54 \%$, a growth rate $\geq+2$ SDS in $46 \%$ and bone age advance $\geq 2$ years in $33 \%$. There is a heterogeneity in the pattern of presentation ranging from rapidly progressing puberty to a slowly progressive form, or even complete regression in pubertal signs and no need for treatment (13).

It has been suggested that thelarche variants represent different positions along a continuum of hypothalamic GnRH neuronal activation (14). The natural history of progression from premature thelarche (defined by bone age advancement within 2 s.D. of normal, normal growth rate and FSH-predominant responsiveness to acute $\mathrm{GnRH}$ stimulation) to CPP was investigated in 100 girls, with a mean age of 5.1 years (15). Their follow-up indicated a 14\% progression rate. Some clarity has been achieved through the European Society for Paediatric Endocrinology classification of endocrine diagnoses (16). Early onset of premature thelarche occurring before 3 years of age generally regresses between 6 months and 6 years after onset. A later onset is usually a slowly progressive form of precocious puberty which may even regress. Both forms need regular follow-up but treatment is rarely indicated.

\section{Precocious puberty: assessment}

The following components need to be included in the evaluation of a child presenting with precocious puberty.

(i) Chronology of the appearance of secondary sexual characteristics before the age of 8 years in a girl (B2 stage) or before the age of 9 years in a boy (G2 and/or testicular volume $\geq 4 \mathrm{ml}$ ). The rate of progression of pubertal signs and any accompanying growth spurt (the 'tempo' of puberty) is recorded. Symptoms suggestive of an intracranial lesion such as headache and visual disturbance should be noted.

(ii) Physical examination is focused on quantifying puberty by Tanner staging and anthropometric measurements are plotted on appropriate growth charts. The full examination includes neurological evaluation and dermatological features of diagnostic pointers for conditions such as neurofibromatosis and McCune-Albright syndrome.

(iii) Bone age assessment provides an indication of skeletal advancement from excess sex steroids and can also be used to estimate final height.

(iv) Ultrasound of the ovaries and testes may reveal the presence of a tumour as a non-central or gonadotrophin-independent cause of the precocious puberty. Pelvic ultrasound in girls may differentiate between premature thelarche and precocious puberty, particularly in relation to uterine size.

(v) The key endocrine investigation is to determine the $\mathrm{LH}$ and $\mathrm{FSH}$ response to acute $\mathrm{GnRH}$ stimulation in order to distinguish between central and non-central (peripheral) forms of precocious puberty. Several test protocols are described; the one commonly used is measurement of $\mathrm{LH}$ and FSH at baseline and 20 and $60 \mathrm{~min}$ after $100 \mu \mathrm{g} \mathrm{GnRH}$ given intravenously. It is essential to employ sensitive gonadotrophin assays; indeed, this may permit differentiation by analysis of basal LH levels only (17).

(vi) Magnetic resonance imaging of the brain is indicated in all boys with CPP, given the high prevalence of organic causes in this group. Most centres would probably also routinely perform this imaging in all girls with precocious puberty, although the prevalence of an organic lesion is much lower when early puberty presents after 6 years of age (18).

A classification of the causes of precocious puberty is traditionally based on a subdivision into gonadotrophindependent and gonadotrophin-independent categories, the acute $\mathrm{GnRH}$ stimulation test "underpinning this subdivision'. Table 1 lists causes of precocious puberty according to such a classification. The remainder of this review refers to gonadotrophin-dependent precocious puberty in view of the focus on $\mathrm{GnRH}$ analogues.

\section{Indications for treatment with GnRHa}

A number of applications of GnRHa treatment apply in paediatric and adolescent practice. Precocious puberty 
Table 1 Classification of precocious puberty.

\begin{tabular}{l} 
Gonadotrophin dependent \\
CNS lesions \\
Hypothalamic hamartoma \\
Tumours: optic glioma, germ cell tumour, astrocytoma \\
Congenital malformations: arachnoid cyst, hydrocephalus, \\
neural tube defect \\
Acquired: head trauma, cranial irradiation, infection, perinatal \\
asphyxia \\
Non-CNS lesion \\
Idiopathic \\
Activating KISS1 and GPR54 \\
Endocrine disruptor exposure; excess endogenous steroids \\
(e.g. CAH) \\
Gonadotrophin independent \\
Gonadal lesions \\
Leydig cell tumour, granulosa cell tumour \\
Activating LH receptor mutation (testotoxicosis) \\
GNAs gene activating somatic mutation (McCune-Albright \\
syndrome) \\
Adrenal tumours \\
hCG secreting tumours \\
Congenital adrenal hyperplasia \\
Long-standing, untreated primary hypothyroidism \\
Exogenous sex steroids \\
Pubertal variants \\
Premature thelarche \\
Premature adrenarche \\
Isolated premature menarche \\
\hline
\end{tabular}

poses the problems of inappropriate early biological maturation at variance with psychological immaturity. Significant impairment of final height in untreated CPP has dominated the rationale for intervening with $\mathrm{GnRH}$ treatment (19). It has been calculated that height loss is of the order of 20 and $12 \mathrm{~cm}$ in boys and girls respectively (20). Few studies have evaluated psychosocial outcome following early or precocious puberty, but a long-term Swedish study reported more antisocial behaviour in adolescence and lower academic achievement in adulthood (21). There is evidence that normal, early maturing adolescents are more likely to have sexual intercourse and engage in substance abuse at an earlier age than normal or late maturing adolescents (22). GnRHa treatment may be indicated to halt menses for hygienic reasons in some girls with severe cerebral palsy or developmental retardation. Girls with cerebral palsy start puberty earlier than normal girls but menarche is delayed by about 1 year (23). A number of options are available to manage menstruation and contraception in adolescents with severe learning difficulties (24). Depo-Provera (Pfizer) is probably less cumbersome than GnRHa in the longer term; surgical intervention is seldom necessary. GnRHa is now used to suppress puberty in adolescents with gender dysphoria and contemplating cross-hormone treatment and later genital surgery (25). Current controversies centre on whether such treatment should be instigated at an early Tanner stage or when puberty is almost complete (26). The following section concentrates solely on the application of GnRHa treatment in the management of precocious puberty.

\section{GnRHa treatment}

Several preparations of GnRHa are currently available. These include Leuprorelin, Triptorelin and Goserelin, which are each available as monthly and 3-monthly depot preparations. A 12-month implant (Histrelin) is also available but currently only in the United States (27). Short-acting preparations that need to be delivered one to three times daily by nasal spray are also available but are not as efficient as sustained release preparations in suppressing gonadotrophin secretion. The rationale of continuous GnRH secretion for the suppression of pubertal development is that the pituitary gonadotrophs are subject to prolonged rather than intermittent (pulsatile) exposure to the RH (7). Following an initial 'flare' in LH and FSH secretion, the pituitary gonadotroph receptors become desensitized and LH and FSH secretion is subsequently suppressed. To achieve prolonged agonist activity, the GnRH decapeptide is modified by replacing the sixth amino acid, glycine, with a hydrophobic D-amino acid. Treatment is usually started with a monthly depot preparation given in a dose of $3.75 \mathrm{mg}$ by s.c. or i.m. injection. A withdrawal bleed may occur in some girls following the first GnRHa injection. Some centres co-administer cyproterone acetate for a few weeks to counter the effects of the initial 'flare' in gonadotrophin secretion before desensitization is established. The acute GnRH stimulation test is repeated after a few months to determine whether LH and FSH levels are suppressed. Later, it may be possible to maintain adequate gonadotrophin suppression using a 3-monthly long-acting preparation, using a dose of $11.25 \mathrm{mg}$. Triptorelin (Decapeptyl SR) is the only 3-monthly injection licensed for use in CPP. Table 2 illustrated its effectiveness in suppressing serum LH and FSH concentrations. Oestradiol and testosterone levels were suppressed to prepubertal levels by month 3 in 96 and $70 \%$ of girls and boys respectively. If suppression of hormone

Table $2 \mathrm{GnRH}$-stimulated concentrations of $\mathrm{LH}$ and FSH before and after $\mathrm{GnRHa}$ treatment.

\begin{tabular}{|c|c|c|c|}
\hline & \multicolumn{2}{|c|}{ LH } & \multirow[b]{2}{*}{$\begin{array}{c}\text { FSH peak } \\
(\mathrm{IU} / \mathrm{l})\end{array}$} \\
\hline & $\begin{array}{l}\text { LH peak } \\
\leq 3 \mathrm{IU} / \mathrm{l} \\
n / N(\%)\end{array}$ & $\begin{array}{l}\text { Peak } \\
(I U / I)\end{array}$ & \\
\hline \multicolumn{4}{|c|}{ ITT population $(n=64)$} \\
\hline Baseline & $0 / 64(0)$ & $21.0 \pm 13.7$ & $10.9 \pm 4.7$ \\
\hline Month 3 & $53 / 62(85)$ & $3.1 \pm 6.3^{*}$ & $2.6 \pm 3.4^{*}$ \\
\hline Month 6 & $60 / 62(97)$ & $1.3 \pm 0.9^{*}$ & $1.7 \pm 1.1^{*}$ \\
\hline Month 12 & $56 / 59(95)$ & $1.7 \pm 2.9^{*}$ & $2.0 \pm 1.7^{*}$ \\
\hline \multicolumn{4}{|c|}{ Per-protocol population $(n=38)$} \\
\hline Baseline & $0 / 38(0)$ & $21.3 \pm 14.5$ & $10.7 \pm 4.7$ \\
\hline Month 3 & $37 / 38$ (97) & $1.2 \pm 0.7^{*}$ & $1.4 \pm 0.8^{*}$ \\
\hline Month 6 & $37 / 38(97)$ & $1.2 \pm 0.7^{*}$ & $1.7 \pm 1.1^{*}$ \\
\hline Month 12 & $37 / 38(97)$ & $1.7 \pm 3.2^{*}$ & $2.2 \pm 1.9^{*}$ \\
\hline
\end{tabular}

Results are given as mean + s.D. ${ }^{*} P<0.001$ with respect to baseline. ITT refers to intend-to-treat population; the per-protocol population is a subset of the ITT population and had received all four quarterly injections. (Reproduced from Ref. (28), with permission). 
levels is insufficient, the frequency of GnRHa injections can be increased; the alternative is to revert to the 1-monthly depot preparation, but at a higher dose.

\section{Effect of GnRHa treatment on final height}

Despite GnRH analogue treatment being used in precocious puberty for more than 20 years, there are no randomized controlled trials to evaluate the effect of GnRHa on a final height compared with untreated controls. The majority of studies compare pretreatment predicted final height data with final attained adult height. The effectiveness of GnRHa treatment can probably only be evaluated by comparing final height data in current treated cohorts with historical data from untreated patients (20).

The analysis of final height outcome data is compounded by a number of factors that influence accuracy and relevance of the end result. Comparing historical with contemporary data may be affected by the influence of secular trends in human growth over the past 25 years. Many studies have had to rely on height prediction, rather than actual final height, to evaluate the effect of treatment intervention (29). The use of bone ages is insufficiently reliable, particularly when skeletal maturation is markedly advanced at presentation. Nevertheless, the use of Bayley and Pinneau tables for average children appears to be the preferred methodology for height prediction (30).

As in many endocrine disorders where final height is a measure of response to treatment, the age at which treatment is initiated, its duration and the magnitude of bone age advancement at the start of treatment are influential factors. Unlike disorders treated with $\mathrm{GH}$, the dose of GnRHa is irrelevant, as long as adequate gonadotrophin suppression is achieved for the duration of the treatment. All these heterogeneous factors make the formulae used for predicted heights of disputable value. In a retrospective single-centre study of 87 girls with idiopathic CPP treated for 3-8 years, adult height was $159.8 \pm 5.3 \mathrm{~cm}$ and represented a $9.5 \pm 4.6 \mathrm{~cm}$ increment in height when compared with predicted height using Bayley and Pinneau tables for average children (31).

Overall, the majority of studies indicate some beneficial effect of GnRHa treatment on final height in girls when compared with initial height predictions (20). The increment can range from 3 to $10 \mathrm{~cm}$, although realistically, a height gain of 4-6 cm after at least 3-4 years of GnRHa treatment is the estimate for a girl with CPP. A shorter interval between the age of onset of puberty and starting treatment was a determining factor for achieving normal adult height (32). The best independent predictor of growth during the period of GnRHa therapy in girls is bone age (33). This observation can be interpreted by assuming that the slowing of growth during treatment is a function of premature growth plate senescence induced by previous exposure to excess oestrogens.

Outcome data for final height are even less established for boys in whom the incidence of precocious puberty is lower than in girls. An analysis of final height from 11 studies showed a remarkably varied mean height gain of -1.8 to $15.0 \mathrm{~cm}$ (29). The variability must be explained, in part, by the small numbers in most of the study groups, but an analysis of 26 boys from three European studies showed a height gain of $6.2 \mathrm{~cm}$ (s.D. $8.7 \mathrm{~cm}$ ). As was the case with treated girls, the height increment was greater when treatment was started early. GnRHa treatment in the case of adopted children with early puberty leads to a moderate height gain of $5.2 \mathrm{~cm}$ after 3 years of treatment (34).

\section{Long-term outcome data after GnRHa treatment}

More than 20 years of experience with GnRHa treatment in CPP has provided important data on outcome regarding reproduction, body mass index and bone mineral density. There is reassuring evidence that gonadal function is reactivated soon after cessation of treatment. Again, the information is confined mainly to females. Mean time to menarche post-treatment is 16 months with normal pattern of menses; reproductive potential appears normal in young adulthood with healthy offspring of those who became pregnant (31, $35)$. There appears to be no increased risk of ovulatory dysfunction associated with factors such as hirsutism and polycystic ovary syndrome, and GnRHa treatment per se does not lead to obesity. However, fat mass is increased at the start of and during early treatment, but normalizes thereafter (36). Similarly, increased bone mineral density at the outset had normalized for both bone age and chronological age within 2 years of treatment cessation.

While there is evidence that early puberty can be associated with aberrant sexual activities and antisocial behaviour in late adolescence, there are no data on the effects of any treatment intervention on longer term outcome with respect to any psychopathologies. Embarking on treatment for the individual child with $\mathrm{CPP}$ is not underpinned by any comprehensive evaluation of the long-term outcome data at a population level.

\section{Conclusions}

It is estimated that precocious puberty affects between 1 in 5000 and 1 in 10000 children and a high female to male ratio (37). There is consensus, at least in Europe, on the chronological age points below which onset of puberty is considered to be precocious in either sex. Puberty is a neurobiological phenomenon characterized by 
re-awakening of the GnRH pulse generator; why this should occur on average at around 11 years of age in the human remains a biological mystery (38). The causes of precocious puberty are broadly subdivided according to a functional classification based on gonadotrophin dependence (central) and gonadotrophin non-dependence (peripheral). Central causes are amenable to management with GnRH analogues that operate on physiological principles by desensitizing the signalling pathway to gonadotrophin production. The aims of the treatment are to halt and perhaps reverse the secondary sex characteristics of puberty, prevent early onset of menses in girls and attenuate the loss of height potential consequent upon advanced skeletal maturation. These are the physical goals of the treatment intervention, but the psychosocial aspects are equally important to enable the child and family to cope better with the 'mismatch' between physical and emotional development. Gonadal steroid production is efficiently suppressed with GnRHa treatment, and menarche can be delayed until an age and developmental stage of choice agreed by the family and physician. There are no adverse effects in the longer term with respect to reproductive potential. Enhancing final height is not such a success story. This had encouraged a polypharmacy approach with the addition of GH to enhance growth velocity during the slow phase of growth while on GnRHa treatment and aromatase inhibitors (such as letrozole and anastrozole) to delay oestrogeninduced closure of the growth plate. This 'belt and braces' approach may be beneficial in individual cases, but there are no systemic controlled trials of its effectiveness on final height. Children with precocious puberty have to cope with the body image at variance with their chronological developmental stage within the context of their family, friends and in education. It is essential that included in the management of precocious puberty is supportive counselling comprising expertise in psychosocial aspects of developmental behaviour (39).

\section{Disclosure}

This paper forms part of a European Journal of Endocrinology supplement, supported by Ferring Pharmaceuticals. The authors disclose: no potential conflicting relationship with Ferring. This article was subject to rigorous peer review before acceptance and publication. The Symposium included a presentation by Dr JC Carel on the use of GnRH analogues in precocious puberty. Unfortunately, Dr Carel was unable to produce a manuscript emanating from his presentation for publication in the supplement. In view of the importance of the subject of precocious puberty in the clinical application of GnRH analogues, this review article was prepared to complete the trio of articles relating to GnRH analogues. The authors confirm that the article was prepared independently of the content of the presentation delivered by Dr Carel.

\section{References}

1 Huirne JA, Lambalk CB, van Loenen AC, Schats R, Hompes PG, Fauser BC \& Macklon NS. Contemporary pharmacological manipulation in assisted reproduction. Drugs 200464 297-322.
2 Buck Louis GM, Gray LE Jr, Marcus M, Ojeda SR, Pescovitz OH, Witchel SF, Sippell W, Abbott DH, Soto A, Tyl RW, Bourguignon JP, Skakkebaek NE, Swan SH, Golub MS, Wabitsch M, Toppari J \& Euling SY. Environmental factors and puberty timing: expert panel research needs. Pediatrics 20083 (Suppl 3) S192-S207.

3 Gluckman PD \& Hanson MA. Evolution, development and timing of puberty. Trends in Endocrinology and Metabolism 200617 7-12.

4 Seminara SB, Messager S, Chatzidaki EE, Thresher RR, Acierno JS Jr, Shagoury JK, Bo-Abbas Y, Kuohung W, Schwinof KM, Hendrick AG, Zahn D, Dixon J, Kaiser UB, Slaugenhaupt SA, Gusella JF, O'Rahilly S, Carlton MBL, Crowley WF Jr, Aparicio SAJR \& Colledge WH. The GPR 54 gene as a regulator of puberty. New England Journal of Medicine 2003349 1614-1627.

5 Silveria LFG, Santos MAG \& Brito VN. Two KISS1 mutations associated with gonadotrophin-dependent precocious puberty. (abstract FC2-76) Hormone Research 200870 (Suppl 2) 20.

6 Roa J, Aguilar E, Dieguez C, Pinilla L \& Tena-Sempere M. New frontiers in kisspeptin/GPR 54 physiology as fundamental gatekeepers of reproductive function. Frontiers in Neuroendocrinology 200829 48-69.

7 Lahlou N, Carel J, Chaussain J \& Roger M. Pharmacokinetics and pharmacodynamics of $\mathrm{GnRH}$ agonists: clinical implications in pediatrics. Journal of Pediatric Endocrinology and Metabolism 2000 13 (Suppl 1) 723-737.

8 Herman-Giddens ME, Slora EJ, Wasserman RC, Bourdony CJ, Bhapkar MV, Koch GG \& Hasemeier CM. Secondary sexual characteristics and menses in young girls seen in office practice: a study from the Pediatric Research in Office Settings Network. Pediatrics 199799 505-512.

9 Mul D, Oostdijk W \& Drop SL. Early puberty in adopted children. Hormone Research 200257 1-9.

10 Teilmann G, Pedersen CB, Skakkebaek NE \& Jensen TK. Increased risk of precocious puberty in internationally adopted children in Denmark. Pediatrics 2006118 e391-e399.

11 Teilmann G, Parent A-S, Skakkebaek NE \& Bourguignon JP. Precocious puberty in adopted girls. In When Puberty is Precocious. Scientific and Clinical Aspects, pp 443-459. Eds OH Pescovitz \& E Walvoord, Totowa, New Jersey: Humana Press Inc, 2007.

12 Prete G, Couto-Silva AC, Trivin C \& Brauner R. Idiopathic central precocious puberty in girls: presentation factors. BMC Pediatrics 2008827.

13 Carel JC \& Leger J. Clinical practice. Precocious puberty. New England Journal of Medicine 2008358 2366-2377.

14 Pescovitz OH, Hench KD, Barnes KM, Loriaux DL \& Cutler GB Jr. Premature thelarche and central precocious puberty: the relationship between clinical presentation and the gonadotropin response to luteinizing hormone-releasing hormone. Journal of Clinical Endocrinology and Metabolism 198867 474-479.

15 Pasquino AM, Pucarelli I, Passeri F, Segni M, Mancini MA \& Municchi G. Progression of premature thelarche to central precocious puberty. Journal of Pediatrics 1995126 11-14.

16 Wit JM, Ranke M \& Kelnar CJH Eds. ESPE Classification of Paediatric Endocrine Diagnoses. Karger. Basel: Karger, 2007.

17 Resende EAMR, Lara BHJ, Reis JD, Ferreira BP, Pereira GA \& Borges MF. Assessment of basal and gonadotropin-releasing hormone-stimulated gonadotropins by immunochemiluminometric and immunofluorometric assays in normal children. Journal of Clinical Endocrinology and Metabolism 200792 1424-1429.

18 Chalumean M, Hadjiathanasiou CG, Ng SM, Cassio A, Mul D, Cisternino M, Partsch CJ, Theodoridis C, Didi M, Cacciari E, Oostdijk W, Borghesi A, Sippell WG, Bréart G \& Brauner R. Selecting girls with precocious puberty for brain imaging: validation of European evidence-based diagnosis rule. Journal of Pediatrics $2003143445-450$.

19 Sigurjonsdottir TJ \& Hayles AB. Precocious puberty. A report of 96 cases. American Journal of Diseases of Children 1968115 309-321.

20 Carel JC, Lahlou N, Roger M \& Chaussain JL. Precocious puberty and statural growth. Human Reproduction Update 200410 135-147. 
21 Johansson T \& Ritzen EM. Very long-term follow-up of girls with early and late menarche. Endocrine Development 20058 126-136.

22 Tremblay L \& Frigon JY. Precocious puberty in adolescent girls: a biomarker of later psychosocial adjustment problems. Child Psychiatry and Human Development 200536 73-94.

23 Worley G, Houlihan CM \& Herman-Giddens ME. Secondary sexual characteristics in children with cerebral palsy and moderate to severe motor impairment: a cross-sectional survey. Pediatrics 2002 $110897-902$.

24 Albanese A \& Hopper NW. Suppression of menstruation in adolescents with severe learning difficulties. Archives of Disease in Childhood 200792 629-632.

25 Cohen-Kettenis PT, Delemarre-van de Waal HA \& Gooren LJ. The treatment of adolescent transsexuals: changing insights. Journal of Sexual Medicine 20085 1892-1897.

26 Giordano S. Lives in a chiaroscuro. Should we suspend the puberty of children with gender identity disorder? Journal of Medical Ethics 200834 580-584.

27 Eugster EA, Clarke W, Kletter GB, Lee PA, Neely EK, Reiter EO, Saenger P, Shulman D, Silverman L, Flood L, Gray W \& Tierney D. Efficacy and safety of histrelin subdermal implant in children with central precocious puberty: a multicenter trial. Journal of Clinical Endocrinology and Metabolism 200792 1697-1704.

28 Carel JC, Blumberg J, Seymour C, Adamsbaum C \& Lahlou N for the Triptorelin 3-month CPP Study Group. Three-month sustained-release Triptorelin $(11.25 \mathrm{mg})$ in the treatment of central precocious puberty. European Journal of Endocrinology 2006154 119-124.

29 Bertelloni S \& Mul D. Treatment of central precocious puberty by GnRH analogs: long-term outcome in men. Asian Journal of Andrology 200810 525-534.

30 Kauli R, Galatzer A, Kornreich L, Lazar L, Pertzelan A \& Laron Z. Final height of girls with central precocious puberty, untreated versus treated with cyproterone acetate or GnRH analogue. A comparative study with re-evaluation of predictions by the Bayley-Pinneau method. Hormone Research 1997 47 54-61.

31 Pasquino AM, Pucarelli I, Accardo F, Demiraj V, Segni M \& Di Nardo R. Long-term observation of 87 girls with idiopathic central precocious puberty treated with gonadotropin-releasing hormone analogs: impact on adult height, body mass index, bone mineral content, and reproductive function. Journal of Clinical Endocrinology and Metabolism 200893 190-195.

32 Brito VN, Latronico AC, Cukier P, Teles MG, Silveira LFG, Arnhold IJP \& Mendonca BB. Factors determining normal adult height in girls with gonadotropin-dependent precocious puberty treated with depot gonadotropin-releasing hormone analogs. Journal of Clinical Endocrinology and Metabolism $2008932662-2669$.

33 Weise M. Flor A, Barnes KM, Cutler GB Jr \& Baron J. Determinants of growth during gonadotropin-releasing hormone analog therapy for precocious puberty. Journal of Clinical Endocrinology and Metabolism 200489 103-107.

34 Mul D, Oostdijk W, Waelkens JJ \& Drop SL. Final height after treatment of early puberty in short adopted girls with gonadotrophin releasing hormone agonist with or without growth hormone. Clinical Endocrinology 200563 185-190.

35 Heger S, Muller M, Ranke M, Schwarz HP, Waldhauser F, Partsch CJ \& Sippell WG. Long-term GnRH agonist treatment for female central precocious puberty does not impair reproductive function. Molecular and Cellular Endocrinology 2006 254-255 217-220.

36 van der Sluis IM, Boot AM, Krenning EP, Drop SLS \& de Muinck Keizer-Schrama S. Longitudinal follow-up of bone density and body composition in children with precocious or early puberty before, during and after cessation of GnRH agonist therapy. Journal of Clinical Endocrinology and Metabolism 200287 506-512.

37 Partsch JC, Heger S \& Sippell WG. Management and outcome of central precocious puberty. Clinical Endocrinology 200256 129-148.

38 Hughes IA \& Kumanan M. A wider perspective on puberty. Molecular and Cellular Endocrinology 2006 254-255 1-7.

39 Mrug S, Elliott M, Gilliland MJ, Grunbaum JA, Tortolero SR, Cuccaro P \& Schuster M. Positive parenting and early puberty in girls: protective effects against aggressive behaviour. Archives of Pediatrics \& Adolescent Medicine 2008162 781-786.

Received 23 October 2008

Accepted 29 October 2008 